\title{
O JORNAL ZERO HORA E SUA AUDIÊNCIA NO CONTEXTO DA CONVERGÊNCIA JORNALÍSTICA ${ }^{1}$
}

\author{
THE NEWSPAPER ZERO HORA AND ITS AUDIENCE \\ IN THE CONTEXT OF JOURNALISTIC CONVERGENCE
}

\author{
PERIÓDICO ZERO HORA Y SU AUDIENCIA \\ EN EL CONTEXTO DE LA CONVERGENCIA PERIODÍSTICA
}

Cristiane Lindemann

Dra., UNISC

cristiane_lindemann@yahoo.com.br

Ana Claudia Gruszynski
Dra., UFRGS
anagru@gmail.com

\section{Resumo}

Considerando o contexto de convergência jornalística, problematiza-se a permeabilidade do jornalismo vinculado a empresas tradicionais de comunicação a partir do viés da audiência, tomando como objeto empírico o jornal Zero Hora (ZH). Com base em dados obtidos pela pesquisa bibliográfica e documental, observação dos processos de trabalho na redação, entrevistas e análise de edições exemplares, avalia-se de que modo o leitor vem influenciando na atividade jornalística. Observou-se que o projeto de inserção da audiência na produção de conteúdo divulgado pelos gestores em 2013 (identificado com a Editoria do Leitor) restringiu as intervenções da audiência aos espaços já tradicionais. Os resultados evidenciam assimetria nas forças que orientam o processo de convergência em $\mathrm{ZH}$, sendo que a permeabilidade do público funda-se no polo econômico do jornalismo.

Palavras-chave: Leitor. Zero Hora. Convergência jornalística.

\begin{abstract}
Considering the context of journalistic convergence, we problematize the permeability of journalism linked to traditional communications companies from the perspective of the audience, having as an empirical object the newspaper Zero Hora $(\mathrm{ZH})$. Based on data obtained by documental and bibliographical research, observation of the work process in the newsroom, interviews and the analysis of exemplary editions, we evaluate the way the reader has influenced the journalistic activity. We observed that the project of the insertion of the audience in the production of content divulged in 2013 by managers (identified as Reader's Department) restricted the interventions of the audience to already traditional spaces. The results outline the asymmetry of forces that guide the process of convergence in $\mathrm{ZH}$, considering that the audience's permeability is founded on the economical side of journalism.
\end{abstract}

\footnotetext{
${ }^{1} \mathrm{O}$ presente artigo foi apresentado no encontro da Associação Brasileira de Pesquisadores em Jornalismo
} realizado em 2014. 
Keywords: Reader. Zero Hora. Convegence. Journalistic convergence.

\section{Resumen}

Teniendo en cuenta el contexto de la convergencia periodística, se problematiza la permeabilidad del periodismo asociado con las compañías tradicionales de comunicación desde la visión de la audiencia, considerando como objeto empírico el periódico Zero Hora (ZH). Con base en los datos obtenidos de la investigación bibliográfica y documental, la observación de los procesos de trabajo en la redacción, entrevistas y análisis de ediciones ejemplares, se evalúa cómo el lector está influyendo en el periodismo. Se observó que el proyecto de inserción de la audiencia en la producción de contenidos publicados por los gestores en el 2013 (identificados con la Editoria del Lector) restringió las intervenciones de la audiencia en los espacios ya tradicionales. Los resultados muestran asimetría en las fuerzas que manejan el proceso de convergencia en $\mathrm{ZH}$ ya que la permeabilidad de la audiencia esta baseada en el polo económico del periodismo.

Palabras clave: Lector. Zero Hora. Convergencia periodística.

\section{INTRODUÇÃO}

O contexto atual de convergência tem acarretado significativas mudanças no campo jornalístico, tensionando aspectos da cultura profissional, das rotinas produtivas, do funcionamento das empresas e até da própria função do jornalismo. Como uma prática social que coloca em circulação o conhecimento proveniente de diferentes campos, o jornalismo assume a função de produtor de conhecimento (GENRO FILHO, 1989; MEDITSCH, 1997), uma vez que leva informações aos leitores, por meio da representação do real; e também de vigilante do poder público, pois ao retratar o que se passa no âmbito sociopolítico, protege os cidadãos contra os abusos dos governantes (TRAQUINA, 2007).

O desenvolvimento dos meios digitais, das conexões facilitadas à internet e da web 2.0 acarretam em um maior acesso à informação. Muitos acontecimentos são informados em publicações sem a intervenção de jornalistas, em blogs, redes sociais ou sites colaborativos, por exemplo. Percebemos, ainda, uma preocupação das empresas jornalísticas em absorver materiais desta ordem, criando mecanismos internos como seções para publicar fotos, textos, vídeos ou áudios enviados pelos leitores. Além dos espaços dentro dos portais de informação na web, o conteúdo proveniente das audiências pode vir a ocupar as páginas impressas de jornais tradicionais ou entrar na programação de rádio e de televisão - não apenas nos espaços de opinião, como já é de praxe, mas também na pauta do dia.

Temos a inserção de novos atores no processo de produção noticiosa, provocando uma reestruturação das redações tradicionais em termos de fluxo informacional, de relações entre 
os profissionais e também de critérios de noticiabilidade. O newsmaking, portanto, é diretamente afetado pelas mudanças em curso. Tendo isso em vista, entendemos que o jornalista já não é mais figura centralizadora da produção noticiosa atualmente. Isso porque o processo rígido, de caráter industrial, vem cedendo espaço para modelos descentralizados, que envolvem outros sujeitos - as audiências, cuja formação pode ou não ser jornalística - tanto na coleta, quanto na construção e distribuição das informações (MOTTA, 2014).

Consideramos, portanto, um panorama em que o conceito de audiência e a teoria do newsmaking - relativa aos estudos do "fazer jornalístico", que envolve as pessoas intervenientes no processo de produção de informação, o clima institucional, as rotinas, os valores, as convenções profissionais e os critérios de noticiabilidade (SOUSA, 1998) merecem ser revistos a partir do fenômeno da convergência. Se antes cabia apenas ao jornalista a tarefa de escolher o que seria relevante para o seu público ler, definindo as fontes a serem consultadas, rejeitando determinadas pautas por questões ideológicas, econômicas ou limitação de espaço/tempo, as circunstâncias atuais tensionam tais parâmetros. Agora o primeiro ator a filtrar a informação e dar contorno ao acontecimento - com a definição do ângulo para captura de uma imagem, por exemplo - pode ser também um membro da audiência. Em contrapartida, os leitores de jornais tradicionais, que pagam para consumi-los, depositam credibilidade em veículos produzidos por profissionais, não por amadores. Portanto, em consonância com Motta (2014, p. 10), consideramos que

[...] não significa que as empresas jornalísticas tenham perdido sua centralidade na produção da visibilidade, nem que tenham perdido (ainda) a hegemonia do fazer jornalístico. Significa apenas que o campo está cada vez mais tensionado. O jogo de interesses parece ter se tornado mais público, e as empresas mais permeáveis. Em seu processo produtivo, o jornalismo profissional necessita hoje fazer mais concessões e negociações.

Buscando problematizar a permeabilidade do jornalismo vinculado a empresas tradicionais de comunicação a partir do viés da audiência, tomaremos como objeto empírico o jornal Zero Hora (ZH), veículo pertencente ao Grupo Rede Brasil Sul (RBS), que tem posição hegemônica no mercado de comunicação da região Sul. Com base em dados obtidos através de pesquisa bibliográfica e documental, assim como observação dos processos de trabalho na redação, entrevistas e análise de edições exemplares ${ }^{2}$, iremos avaliar de que modo o leitor vem influenciando estas “concessões e negociações” no âmbito da produção ${ }^{3}$ para assim refletirmos

\footnotetext{
2 Os procedimentos metodológicos integraram as pesquisas de Cristiane Lindemann e Ana Gruszynski, realizadas junto ao Laboratório de Edição, Cultura e Design (LEAD). São trazidos para o artigo alguns dos dados nelas levantados.

${ }^{3}$ Não se trata, portanto, de um estudo de recepção, mas de avaliação dos espaços da audiência a partir dos discursos da empresa, da organização de redação e seus fluxos de trabalho, do produto editorial.
} 
sobre as mudanças acerca do fazer jornalístico contemporâneo.

\section{ZERO HORA NO CONTEXTO DA CONVERGÊNCIA JORNALÍSTICA}

A notícia é a matéria-prima do jornalismo. Informação transformada em mercadoria por meio de um "tratamento que a adapta às normas mercadológicas de generalização, padronização, simplificação e negação do subjetivismo." (MARCONDES FILHO, 1989, p. 13) Os acontecimentos são (re)construídos pelos jornalistas através de uma realidade discursiva, criando uma realidade social e produzindo sentido a partir de regras que regem as rotinas produtivas e também a lógica de mercado. Há, portanto, dois eixos sustentadores que orientam o fazer jornalístico, conforme explica Traquina (2005): um ideológico, em que o jornalismo é encarado como um serviço público que fornece aos cidadãos as informações de que precisam e age como guardião para defendê-los de eventuais abusos de poder; outro econômico, que toma o jornalismo como um negócio e as notícias como uma mercadoria que tem alimentado o desenvolvimento de companhias altamente lucrativas.

Iniciado no século passado, o fenômeno de transformação do jornalismo em negócio, da notícia em mercadoria e dos leitores em consumidores permanece e ingressa no chamado “ciclo flexível do capitalismo mundial” (FONSECA, 2008), marcado pelo desenvolvimento tecnológico e por investimentos em megaempreendimentos de alcance global, com possibilidades de aceleração do tempo de giro do capital - o que conduz as indústrias culturais na direção da convergência tecnológica. Assim, assinala Fonseca (2008), as empresas tradicionalmente dedicadas à produção de conteúdos culturais para mídias específicas, tendem a se transformar em conglomerados multimídia. A lógica comercial perdura, agora em proporções ainda mais salientes, contudo, as brechas para intervenção do público multiplicam-se consideravelmente.

Imerso neste contexto, ZH é exemplar deste processo. Sua primeira edição circulou em 4 de maio de 1964, com a proposta estratégica de contemplar o estado do Rio Grande do Sul. Apesar do caráter localizado, o jornal transformou-se em um dos mais expressivos do Brasil em termos de tiragem. Segundo o Instituto Verificador de Circulação (IVC) ${ }^{4}$, na contagem anual, em 2012, a exemplo do que vinha ocorrendo desde 2010, o veículo ocupou a sexta posição no ranking de jornais mais vendidos no Brasil, com uma média de circulação paga, por ano, de 184.674 exemplares, antecedido pela Folha de São Paulo (SP), Super Notícia (MG), O Globo

\footnotetext{
${ }^{4}$ Endereço eletrônico: www.ivcbrasil.org.br
} 
(RJ), O Estado de São Paulo (SP) e Extra (RJ). Contudo, ZH teve queda no desempenho nos primeiros quatro meses de 2014, passando de 181.772 exemplares diários em janeiro para 174.234 em abril (- 3,59\%). Se comparado a abril de 2013, a redução foi de 4,43\% .

Apesar das oscilações, ZH vem mantendo-se bem colocada no mercado, investindo continuamente em tecnologia e acompanhando os processos de convergência - ou seja, há um esforço no sentido de criar diferentes modelos de negócio que deem conta da complexidade e das mudanças do cenário jornalístico atual. Analisaremos uma destas estratégias, a criação da Editoria do Leitor (2013), e sua extinção com reformulação gráfica e editorial realizada em função do cinquentenário do jornal (2014).

A partir de Palacios e Diaz Nóci (2009), tomaremos a convergência como processo que deve ser analisado a partir de diferentes esferas, um continuum constituído por diversas etapas, cuja meta final seria a integração. Abrange diversos âmbitos, desde a gerência e do modelo de negócio, passando pela cultura organizacional, pelos processos operacionais, até as questões de mercado e relações com o público. Salaverría, Avilés e Masip (2010) a sistematizam em quatro dimensões: tecnológica, empresarial, profissional, editorial, às quais Sábada et al. (2008) agregam os meios - por considerarem que cada um possui uma linguagem e características específicas -, e as audiências - para enfatizar a importância da participação ativa do público.

Nesse sentido, nosso objeto empírico tem uma história conduzida pelo compasso das inovações tecnológicas (LINDEMANN, 2014; GRUSZYNSKI; LINDEMANN; OLIVEIRA, 2014), o que repercute em diferentes setores da instituição (empresarial), nas rotinas produtivas (profissional) e no produto final (editorial). Além disso, diversas iniciativas de ZH envolvendo os leitores têm sido apresentadas pelo jornal nos últimos dois anos (período do nosso estudo), contemplando o eixo que propomos analisar.

\section{ESTRATÉGIAS DE RELACIONAMENTO COM OS LEITORES}

No ano de 2013, ZH investiu fortemente na relação entre jornalistas e audiências, com o propósito de fomentar a produção conjunta de conteúdo. Diversos projetos e ações foram criados para viabilizar a intersecção entre o trabalho profissional e o público, permeando a fronteira entre produção e recepção. $\mathrm{O}$ auge destas iniciativas se deu em junho do referido ano, quando foi criada a Editoria do Leitor, resultante da união entre os setores de

\footnotetext{
${ }^{5}$ Fonte: Coletiva.net. Disponível em: http://migre.me/kwm2n Acesso em: 16 jul.2014.
} 
Relacionamento com o Leitor, Mídias Sociais e Divulgação. O projeto, segundo Marta Gleich (2013), diretora de redação, buscava "dar um salto e colocar ZH num posicionamento diferenciado em termos de relacionamento com o público, começando pelo digital”.

Vale ressaltar que o veículo foi um dos primeiros jornais brasileiros a possuir uma seção de cartas e também um setor exclusivo para atender leitores. A Editoria de Atendimento ao Leitor foi criada em 1991, com duas principais funções: 1) editar uma página fixa diária (página dois), completamente estruturada a partir das intervenções do público; 2) atender leitores no que diz respeito a assuntos editoriais. (MINUZZI, 2007) À época, localizavase na sala de Arte e Fotografia (fora da redação); em 2011 ocorreu a primeira mudança de nome, passando a denominar-se Editoria de Relacionamento com o Leitor, e a equipe passou para dentro da redação, contudo, ocupando posição periférica. Em 2013, a Editoria do Leitor foi articula e passou a ocupar a área central da redação, espaço de visibilidade e de fácil acesso aos demais membros do corpo editorial. O movimento visou indicar simbolicamente que a editoria era tão importante quanto qualquer outra; o leitor no centro do jornal era o significado almejado: "Se a gente faz um jornal para o público, o público tem que estar aqui dentro, então esta é a ideia." (GLEICH, 2013)

A diretora de redação ainda endossa: "acho que o jornal que não se abrir para os leitores e para um conteúdo dosado, está ralado. Nós temos que fazer isso, o público espera isso da gente, essa participação maior, porque é assim que está a vida”. (GLEICH, 2013) Deste modo, além dos meios tradicionais como telefone, e-mail e colunas opinativas, $\mathrm{ZH}$ passou a desenvolver - já em 2012, com vistas ao projeto que passaria a ser executado em 2013 - ações que visavam acompanhar as tendências da web 2.0, apropriando-se do potencial do público no fornecimento de imagens, textos, sugestões de pauta e vídeos. Todo o processo foi divulgado em canais institucionais, como na Carta do Editor, no Blog do Editor ou mesmo nos espaços editoriais, por meio de matérias que visavam, sobretudo, convidar o público a participar reiterando, portanto, o fortalecimento dos contratos de leitura com a audiência, especialmente por meio do seu envolvimento na produção de conteúdo.

Em abril de 2013, por exemplo, dois meses antes da criação da Editoria do Leitor, foi publicado, no Blog do Editor, um texto intitulado "Nos 49 anos de ZH, seja um dos editores do jornal" edição traria em destaque pautas sugeridas e comentadas pelos leitores. Contudo, conforme Barbara Nickel (2013), à época editora de Mídias Sociais e, a partir de junho de 2013, editora

\footnotetext{
${ }^{6}$ Disponível em: http://migre.me/kHrZz Acesso em 10 jun. 2013.
} 
da Editoria do Leitor, “o problema é que o leitor não sabe o que é uma pauta; eles sugerem, na maioria das vezes, temas".

Obviamente, as pessoas não têm obrigação nenhuma de saber, mas isso acaba gerando um grande volume de demandas que as pessoas [jornalistas da redação] acabam automaticamente desprezando, porque tu sabe que das cinquenta mensagens de leitores que vão chegar, duas vão fazer sentido, vão render alguma coisa em termos de pauta. Pelo menos nesse caso específico a gente recebeu umas cem sugestões e conseguiu aproveitar três. (NICKEL, 2013)

Para além de ações pontuais, as funções da Editoria do Leitor incluíam, diariamente, o recebimento (e devido retorno) de aproximadamente 100 e-mails ou contatos via mídias sociais, cujo conteúdo poderia vir a ser utilizado em diversas seções disponibilizadas por ZH nos suportes impresso e digital. Também era tarefa da editoria analisar e arquivar os resultados diários da pesquisa do Call Center, em funcionamento desde 1997, cujos números semanais eram publicados na seção ZH na Semana, junto à página Do Leitor dominical, indicando as notícias ou reportagens mais citadas pelos assinantes quando contatados. Por fim, a equipe ainda tinha o compromisso de agendar visitas de estudantes ou outros grupos interessados em conhecer a redação. Vergara (2013) defendia uma participação maior da editoria na redação, funcionando como uma interface com o que está do lado de fora. A proposta inicial do projeto, que passou a funcionar em junho de 2013, era justamente esta, porém, com ênfase no suporte digital:

[...] hoje a área de Relacionamento [com o Leitor] é muito focada no papel e nos meios tradicionais, como e-mail e telefone. E a gente vê que já surgiram muitas outras formas das pessoas se relacionarem [...]. Nós recebemos cerca de três mil comentários por dia na nossa página de Facebook e isso não está refletido no jornal. As pessoas estão falando do nosso conteúdo nas redes sociais e nas plataformas digitais. [...] nunca se pensou, por exemplo que uma foto poderia ser a capa do jornal de amanhã. Vamos vender, vamos oferecer para a capa, vamos ligar pra esse cara, ouvir mais a história dele e botar isso no site, vender pro editor da capa do site agora, botar na capa do Clic [ClicRBS], fazer bombar, postar no Facebook, ver a repercussão e oferecer uma matéria. Então nosso foco agora é trazer mais para o mundo digital, isso em primeiro lugar. (NICKEL, 2013)

Portanto, este projeto tinha como eixo balizador a valorização do público, a partir de uma concepção de construção conjunta das notícias - que poderia enriquecer o jornalismo com diferentes fontes, discursos plurais e registros factuais -, trazendo à tona um novo elemento que passou a configurar o newsmaking. Os profissionais da redação tinham de considerar as produções dos colaboradores como possíveis pautas ou cases, conforme orientação manifesta pela diretora de redação. 
Na prática de ZH, contudo, conforme indicam os resultados da pesquisa de Lindemann (2014), houve resistência com relação a este processo, de modo que o conteúdo das audiências ficou bastante restrito aos canais colaborativos, no jornal digital, e à página $D o$ Leitor (antiga página dois), no impresso, sem penetrar na pauta do dia, conforme prometia a fala institucional. Segundo pondera Nickel:

A gente trabalha para fechar o jornal. Nesse sentido, o leitor tanto ajuda
quanto dificulta. Quando ele sugere coisas, pode ocorrer de não ter gente
[para apurar e editar o conteúdo] ou de não ter espaço. Outras vezes ele salva
a pátria. E isso a gente vê bastante, é muito frequente algumas editorias
chegarem e dizerem: "vamos fazer tal pergunta nas redes sociais porque a
gente precisa da opinião do leitor para colocar no jornal. Ou, então, vamos
pedir para as pessoas mandarem fotos de tal coisa porque precisamos de foto
de tal coisa." Então é muito instrumental. (NICKEL, 2013)

Tradicionalmente, os modelos produtivos dos meios de comunicação têm critérios próprios de noticiabilidade e a partir deles jornalistas escolhem assuntos considerados relevantes para serem publicados. Se, de um lado, o processo de convergência propicia a abertura de canais para participação e pode estimular o debate público, abrindo espaço para que as audiências opinem e interfiram no processo produtivo, de outro, o tensionamento entre o perfil empresarial, a cultura profissional e o tipo de demanda do público em relação a veículos como $\mathrm{ZH}$, evidencia a complexidade das negociações que se estabelecem, envolvendo também o gerenciamento de aspectos prosaicos.

Por exemplo, conforme Nickel (2013), muitos colaboradores buscam no jornal a solução de problemas práticos ou sociais, como orientações sobre procedimentos para fazer um passaporte ou o lixo da sua rua, que não é coletado corretamente.

O leitor tem dificuldade de entender o que a gente faz e por que uma coisa é notícia ou não é notícia - o que não é uma coisa fácil de se explicar e nem tem uma resposta objetiva, porque se mudar o editor aqui com certeza muda o conceito do que é notícia. Isso a gente já viu até acontecer. (NICKEL, 2013)

Ou seja, mais do que aceitar o leitor como potencial produtor, era preciso encontrar, em meio às colaborações, pautas coerentes à linha editorial. Em Zero Hora, sabemos que o foco não são notícias hiperlocais e estas são as mais ofertadas pelas audiências, segundo Nickel (2013; 2014), Vergara (2013; 2014) e Rossani Thomas (2013) - editora e editora assistente da Editoria do Leitor e editora dos Cadernos de Bairros ${ }^{7}$, respectivamente. Conforme Sodré (2009), o local e o singular induzem emocionalmente à identificação do

\footnotetext{
${ }^{7}$ ZH possuía, até julho de 2014, sete Cadernos de Bairros, sendo que os mais antigos - Bela Vista, Moinhos e o Zona Sul - estavam em circulação desde 2005. As edições dos bairros Petrópolis, Lindóia e Menino Deus existiam desde 2006 e o Mais Canoas, que contemplava a cidade de mesmo nome, situada na região metropolitana de Porto Alegre, desde 2008. Eram semanais e circulavam às quintas e sextas-feiras.
} 
leitor com o acontecimento, contudo, pautas desta ordem podem ou não ser válidas para o cânone da cultura jornalística. Agora, com tantos canais abertos para a participação do público, é possível que elas cheguem às redações. Em ZH, como vimos, isto era recorrente, porém, estes materiais eram publicados basicamente em dois espaços: na seção digital Do Leitor (ainda existente) e nos Cadernos de Bairros (extintos em julho de 2014).

Cerca de sete meses após o lançamento da Editoria do Leitor, em janeiro de 2014, entrevistamos novamente a editora Barbara Nickel e a editora assistente Nereida Vergara, a fim de verificar o que mudou nas rotinas produtivas. Enquanto a equipe anterior, da Editoria de Relacionamento com o Leitor, era composta por quatro pessoas, a nova contava com oito integrantes: uma editora, uma editora assistente, uma jornalista e um estudante de jornalismo responsáveis pela Divulgação, três repórteres (jornalistas) e um assistente de conteúdo (estudante de jornalismo). Dos resultados sentidos até então, Nickel (2014) disse que a principal mudança havia sido o estabelecimento de uma relação mais integrada entre as diferentes plataformas. “A gente está conseguindo juntar mais a página do leitor com as redes sociais, com as ações que a gente faz no site, está tudo mais conectado. Antes as coisas eram muito separadas.” (NICKEL, 2014) Em relação à equipe, considerou que o aprendizado havia evoluído expressivamente. "Quem nunca tinha mexido com a página impressa precisou aprender, assim como quem nunca tinha mexido com redes sociais. Essa evolução em termos de conhecimento foi muito legal". Quanto às mudanças em termos de produto, Nickel (2014) apontou que ocorreu um processo de valorização do site, novamente reforçando o que em 2013 havia sido estipulado como meta para a Editoria do Leitor (ênfase no digital).

Alterações também ocorreram no relacionamento da Editoria do Leitor com as demais editorias de ZH. "Passei a participar de todas as reuniões de pauta, onde é comum surgirem muitas ideias de interatividade com o leitor, como pedir relatos antes de fazer uma matéria, por meio dos murais, por exemplo" (NICKEL, 2014). De acordo com a editora, a comunicação interna melhorou, contudo, o resultado deste progresso no jornal impresso não foi expressivo, o que se justifica, em especial, porque o conteúdo do leitor é, em sua maioria, hiperlocal, interessando a uma comunidade muito pequena. "Por isso é complicado que essa produção conjunta aconteça no papel. Talvez o espaço para isso acontecer seja mesmo na internet e nos Cadernos de Bairros." (NICKEL, 2014)

Em maio de 2014, pouco antes de completar um ano, a Editoria do Leitor foi eliminada em função de uma reforma gráfica e editorial ocorrida em $\mathrm{ZH}$ por ocasião dos seus 50 anos. Porém, a busca pela boa relação com as audiências, conforme Nickel (2014), se coloca como horizonte: "Para esse ano, a grande preocupação é estarmos mais próximos do 
leitor no seguinte sentido: fazer matérias que sejam relevantes para a vida das pessoas" (NICKEL, 2014). A intenção é fazer um jornal que seja útil, a ponto de todos sentirem a necessidade deste produto para conduzir melhor suas tarefas. "E isso significa que a gente precisa ouvir muito mais as pessoas, para saber o que elas querem, o que elas precisam. Prestar atenção no que elas estão dizendo é uma coisa imprescindível.” (NICKEL, 2014) Nesta transição, portanto, o leitor não foi esquecido. Pelo contrário, o estabelecimento de um novo contrato de leitura foi trabalhado de modo enfático, novamente colocando o público como protagonista (GRUSZYNSKI; LINDEMANN; OLIVEIRA, 2014). Entretanto, tudo indica que a inserção da audiência na produção de conteúdo - tão divulgada pelos gestores de ZH em 2013 - não foi a melhor escolha enquanto modelo de negócio a ser seguido.

Wolf (2003) nos indicava o quão secundária é, dentro de uma redação, em pleno ritmo intenso de rotinas diárias, a consideração e preocupação dos jornalistas em relação ao público para o qual escrevem. Muitas decisões ocorrem a partir de critérios vinculados ao profissionalismo ou levam em consideração os próprios pares, do que inferimos uma lógica tensionada ao que a profissão se propõe, que é produzir conteúdo para o leitor (ou, ainda, ouvinte/ telespectador/ internauta), levando a ele conhecimento e informações que sejam úteis ao seu dia a dia. Para o autor, o termo de referência constituído pelo público - ou melhor, pelas opiniões que os jornalistas têm acerca do público - e os limites dessa referência, são um dos aspectos mais interessantes e menos aprofundados da abordagem do newsmaking.

Estes procedimentos, diz Wolf (2003), são válidos nos períodos de rotina, em que o processo produtivo está equilibrado. Contudo, quando há grandes mudanças na redação, a tendência é que os pressupostos acerca do público sejam avaliados com maior precisão, a partir de dados que tornem a imagem deste público mais empírica e menos estereotipada. É justamente o que verificamos em ZH. A execução de novos projetos, como a criação da Editoria do Leitor em 2013 e a grande reformulação gráfica e editorial de 2014, foram fortemente norteadas pela preocupação com os leitores/consumidores. Contudo, apesar de as consequências destes dois projetos afetarem não apenas as rotinas de quem integra as equipes diretamente relacionadas a eles, mas toda a redação, observamos que a preocupação com os leitores ficou restrita a estes profissionais. A proposta de interação intensa com as audiências, objetivo principal da criação da Editoria do Leitor, por exemplo, gerou demandas que passaram a ser atendidas apenas por esta editoria, sem engajamento das demais. $\mathrm{Na}$ visão dos gestores (aqui representados pela entrevistada Marta Gleich) e também das editoras desta equipe, porém, as mudanças deveriam ter permeado toda a redação. 
As iniciativas ainda demonstram que, no processo convergente, a tecnologia permite agilidade, facilidade e criação de novos produtos, influenciando diretamente os modos de produção e acarretando mudanças na rotina dos jornalistas - as quais não são bem recebidas por todos. Muitas tarefas foram suprimidas pela tecnologia, mas, em contrapartida, um único profissional passou a executar múltiplos papéis. Exemplo claro são as contas criadas para cada editoria em diferentes redes sociais, como o Facebook e o Twitter, exigindo que um ou mais jornalistas acumulem a responsabilidade de administrá-las - uma função cujas habilidades, talvez, não lhes fossem familiares até então. Além destes canais, podemos mencionar, ainda, o selo Do Leitor, o Blog do Leitor, as missões Instagram, os murais digitais e os Cadernos de Bairros como exemplos de ferramentas e/ou espaços que passam a fazer parte dos processos produtivos em $\mathrm{ZH}$, exigindo dos jornalistas que estejam atentos às suas possibilidades e modos de uso.

Abertos os caminhos, cabe aos profissionais apropriarem-se desta demanda que se soma à rotina um tanto corrida da redação. Os fluxos, de fato, acontecem. Contudo, mantémse a tendência do espaço do leitor ser limitado à seção de cartas. Das iniciativas outras que visam, conforme o discurso institucional, inserir o público na produção de $\mathrm{ZH}$, detectamos, no suporte impresso, um alto índice de intervenções nos Cadernos de Bairros em oposição a um baixo índice nos demais cadernos e editorias. Inferimos, portanto, que, à exceção dos profissionais que integram a Editoria do Leitor e a Editoria dos Cadernos de Bairros, os demais jornalistas pouco (ou nunca) se envolvem com as audiências, ou restringem esta relação à troca de e-mails e respostas via redes sociais.

\section{CONSIDERAÇÕES FINAIS}

Falta de tempo e de espaço editorial, equipes enxutas, desinteresse e força de uma cultura profissional - aspectos mencionados nas entrevistas realizadas - podem ser apresentados como justificativas para um cenário de passagem no processo de convergência em ZH. Apesar do discurso institucional de potencializar a participação da audiência, a preocupação em manter a linha editorial do jornal e o seu padrão e credibilidade junto ao público (assinantes e anunciantes, em especial), é fator fundamental a ser considerado para a manutenção do contrato de comunicação (CHARAUDEAU, 2007). Além disso, a apropriação destas novas ferramentas de trabalho exige o domínio de técnicas que podem ser desafiadoras, em especial, aos profissionais mais antigos. Wolf (2003) assinala que fatores exteriores à organização do trabalho - como a preparação profissional, os objetivos a atingir e os valores partilhados -, influenciam os processos produtivos. As entrevistas que realizamos, bem como 
a observação das rotinas produtivas, nos permitiram constatar isso nitidamente. Em meio aos processos de mudança que presenciamos, jornalistas foram demitidos com a justificativa de que tinham pouca familiaridade com a internet e/ou dificuldade de lidar com novos modelos de negócio. Entre os que permaneceram, alguns demonstraram facilidade e vontade de lidar com as mudanças, outros não - o que nos leva a mencionar novamente a questão da cultura profissional.

$\mathrm{O}$ projeto de $\mathrm{ZH}$ que analisamos, além de exigir dos jornalistas que aprendessem a lidar com novas tecnologias, esperava, também, que interagissem com o público a partir de uma lógica horizontal - ou seja, que passem a vê-lo como colaboradores no processo produtivo. Como assinala Alsina (2009, p.178), "a determinação do acontecimento, as fontes, o trabalho jornalístico em si são elementos de um processo de produção institucionalizado. A mudança radical de alguns desses elementos traria como consequência a alteração do tipo de imprensa" - o que, acrescentamos, desestabiliza a cultura jornalística. Avaliando tais transformações, Sodré (2009) argumenta que este quadro evidencia uma crise das formas tradicionais de jornalismo. Da nossa análise, inferimos que esta é uma dicotomia vivida em $\mathrm{ZH}$ - o discurso da convergência, aqui analisada sob o aspecto da possibilidade de inserção do público na produção de conteúdo, versus a produção centralizada nos profissionais, carregada de credibilidade e de hábitos de uma prática sedimentada.

Além disso, o imbricamento entre os âmbitos empresarial, tecnológico, profissional e editorial, no caso da proposta estudada, evidencia que há uma assimetria nas forças que orientam o processo de convergência em um veículo com o perfil de $\mathrm{ZH}$, vinculado a um conglomerado multimídia, em que a permeabilidade se dá fundada a partir do pólo econômico do jornalismo. O leitor, nesse sentido, é um consumidor a ser atendido; a questão central parece ser, assim, encontrar modelos rentáveis no quadro de intensas mudanças nas práticas comunicacionais propiciadas pelas mídias e redes digitais. A Editoria do Leitor e as iniciativas a ela relacionadas representaram uma alternativa que não resultou positivamente, mas que assinalam uma experiência relevante de incorporação de uma das potencialidades identificadas com a convergência. Se, por um lado, identifica-se a importância de manter uma estrutura básica do diálogo com o público, por outro o jornal tem a necessidade de conservar sua legitimidade, credibilidade e lucratividade - o que gera tensionamentos no âmbito do newsmaking e incide sobre o produto jornalístico ofertado. A reforma editorial e gráfica implementada maio de 2014, assim, pode ser vista como um marco resultante de várias iniciativas que vinham sendo gestadas/testadas nos últimos anos. 


\section{REFERÊNCIAS}

ALSINA, Miquel Rodrigo. A construção da notícia. Petrópolis, RJ: Vozes, 2009.

CHARAUDEAU, P. Discurso das mídias. São Paulo: Contexto, 2007.

FONSECA, Virginia P. S. Indústria de Notícias: capitalismo e novas tecnologias no jornalismo contemporâneo. Porto Alegre: Editora UFRGS, 2008.

GENRO FILHO, Adelmo. O segredo da pirâmide: para uma teoria marxista do jornalismo. 2.ed. Porto Alegre: Ortiz, 1989.

GLEICH, Marta. Marta Gleich: depoimento, 2013.

GRUSZYNSKI, Ana Cláudia; LINDEMANN, Cristiane; OLIVEIRA, Cássia de. Virando-se por leitores: a reforma editorial e gráfica do jornal Zero Hora no cenário de convergência (2014). Anais do XXXVII Congresso Brasileiro de Ciências da Comunicação. Foz do Iguaçu, PR, 2 a 5 de setembro de 2014.

LINDEMANN, Cristiane. O jornal Zero Hora e seus leitores no contexto de convergência jornalística. Tese de doutorado. Programa de Pós-Graduação em Comunicação e Informação da Universidade Federal do Rio Grande do Sul (UFRGS). Porto Alegre, RS, 2014.

MARCONDES FILHO, Ciro. O capital da notícia: jornalismo como produção social de segunda natureza. São Paulo: Ática, 1989, 188 p.

MEDITSCH, Eduardo. O jornalismo é uma forma de conhecimento? Universidade Federal de Santa Catarina, 1997. Disponível em: 〈www.bocc.ubi.pt>. Acesso em: 28 fev. 2014.

MINUZZI, Marcus Vinícius. Diálogo entre jornalistas e leitores: a participação do público através do ombudsman de imprensa e do Conselho do Leitor de Zero Hora. Tese. Unisinos. São Leopoldo-RS, 2007.

MOTTA, Luiz Gonzaga. Apresentação. In: LEAL, Bruno Souza; ANTUNES, Elton; VAZ, Paulo Bernardo (orgs.). Para entender o jornalismo. Belo Horizonte: Autêntica Editora, 2014. p. $9-10$.

NICKEL, Barbara. Barbara Nickel: depoimento, 2013.

Barbara Nickel: depoimento, 2014.

PALACIOS, Marcos. DIAZ NÓCI, Javier. (Orgs.) Online journalism: research methods. A multidisciplinary approach in comparative perspective. Bilbao: Servicio Editorial de la Universidad del País Vasco, 2009.

SÁBADA, C. et al. Métodos de investigación sobre convergencia periodística. In:

PALACIOS, M.; NOCI, J. Diaz. Metodologia para o estudo dos cibermeios: estado da arte \& perspectivas. Salvador: EDUFBA, 2008. p. 11-27. 
SALAVERRÍA ALIAGA, Ramón; AVILÉS, José Alberto García; MASIP, Pere Masip. Concepto de convergencia periodística. In: GARCÍA, Xosé López; FARIÑA, Xosé Pereira (coords.) Convergência Digital: Reconfiguración de los Medios de Comunicación en España. Santiago de Compostela: Universidade, Servizo de Publicacións e Intercambio Científico, 2010. p. 41-64.

SODRÉ, Muniz. A narração do fato: notas para uma teoria do acontecimento. Petrópolis, RS: Vozes, 2009.

SOUSA, Jorge Pedro. Fotojornalismo performativo: o serviço de fotonotícia da Agência Lusa de Informação. Porto: Edições Universidade Fernando Pessoa, 1998.

THOMAS, Rossani. Rossani Thomas: depoimento, 2013.

TRAQUINA, Nelson. Teorias do jornalismo: porque as notícias são como são. 2 ed. vol 1 . Florianópolis: Insular, 2005.

O que é o Jornalismo. Lisboa: Quimera Editores, 2007.

VERGARA, Nereida. Nereida Vergara: depoimento, 2013.

Nereida Vergara: depoimento, 2013.

WOLF, Mauro. Teorias da comunicação. Tradução de Maria Jorge Vilar de Figueiredo. 8 ed. Lisboa: Presença, 2003.

Original recebido em: 20/04/2015

Aceito para publicação em: 05/11/2015

Cristiane Lindemann

Jornalista. Doutora em Comunicação e Informação pelo Programa de Pós-graduação em Comunicação e Informação da Universidade Federal do Rio Grande do Sul. Pesquisadora junto ao grupo de pesquisa Laboratório de Edição, Cultura e Design (LEAD), cadastrado no CNPq. Professora na Universidade de Santa Cruz do Sul (Unisc).

Ana Gruszynski Jornalista, designer, coordenadora grupo de pesquisa Laboratório de Edição, Cultura e Design (LEAD), cadastrado no CNPq. Professora do Programa de Pós-graduação em Comunicação e Informação da UFRGS e pesquisadora do CNPq.

Esta obra está licenciada sob uma Licença Creative Commons 